\title{
MEDIA INTERAKTIF PENGENALAN BAHASA ISYARAT BISINDO
}

\author{
Bayu Ramadhani Fajri1 ${ }^{*}$, Agariadne Dwinggo Samala ${ }^{2}$, Fadhli Ranuharja ${ }^{3}$ \\ ${ }^{123}$ Program Studi Pendidikan Teknik Informatika, Universitas Negeri Padang, Indonesia \\ Jl. Prof. Hamka Kampus UNP Air Tawar Padang \\ *Corresponding Author: bayurf@unp.ac.id
}

\begin{abstract}
ABSTRAK
Bahasa isyarat merupakan salah satu bentuk komunikasi yang digunakan tunarungu. Bahasa isyarat juga merupakan bentuk aksesibilitas bagi tunarungu agar dapat bersosialisasi dengan orang disekitarnya. Sosialisasi tunarungu dengan orang normal di lingkungannya belum maksimal dikarenakan masyarakat umum belum mengenal bahasa isyarat. Berdasarkan permasalahan tersebut, penelitian ini bertujuan untuk mengembangkan media interaktif pengenalan bahasa isyarat BISINDO berbasis augmented reality bagi masyarakat dalam mendukung masyarakat yang lebih inklusif terhadap tunarungu. Penelitian ini menggunakan pendekatan Research and Development (R\&D). Sampel pada penelitian ini adalah tunarungu yang ikut dalam komunitas Gerkatin Padang, dan masyarakat dari berbagai profesi di Kota Padang. Teknik pengambilan data dilakukan dengan menggunakan teknik angket dan diskusi terfokus. Berdasarkan hasil pengumpulan 100 data persepsi responden dari masyarakat terhadap bahasa isyarat diperoleh: 1) Tingkat mengenal masyarakat terhadap Bahasa isyarat masih rendah yaitu sebesar 57\%,2) Tingkat keterampilan menggunakan Bahasa isyarat masih rendah yaitu sebesar $83 \%$, 3) Tingkat pentingnya Bahasa isyarat menurut masyarakat sebesar $81 \%$, 4) Tingkat kebutuhan masyarakat untuk belajar Bahasa isyarat diperoleh sebesar $88 \%$, dan 5) Tingkat pemilihan media yang tepat untuk belajar Bahasa isyarat, 74\% responden memilih media berupa aplikasi smartphone. Kemduian Validasi dari prototype media interaktif pengenalan Bahasa isyarat BISINDO yang dikembangkan dari segi substansi yaitu kesesuaian Bahasa isyarat pada aplikasi diperoleh penilaian validator sebesar $89.33 \%$, kemudian dari segi media diperoleh nilai validator sebesar $89.67 \%$. Maka dapat disimpulkan bahwa prototype media interaktif berupa aplikasi smartphone yang dikembangkan sangat baik dari segi substansi dan media sehingga sangat layak atau valid untuk digunakan dalam pengenalan Bahasa isyarat BISINDO.
\end{abstract}

Kata kunci: Bahasa Isyarat, BISINDO, Media Interaktif, Augmented Reality

\begin{abstract}
Sign language is the communication that used by the deaf people. Sign language is also a form of accessibility for deaf people to be able to socialize with people around them. Deaf socialization with normal people in the society is not optimal because most of the people does not yet know sign language. Based on these problems, this study aims to develop an interactive media introduction to BISINDO sign language based on augmented reality for the community in supporting a society that is more inclusive of the deaf. This study uses a Research and Development $(R \& D)$ approach. The sample in this study was deaf people who participated in the Gerkatin Padang community, and people from various professions in the city of Padang. The data collection technique was carried out using a questionnaire and a focused group discussion technique. Based on the results of the collection of 100 respondents' perceptions data from the public towards sign language obtained: 1) the level of getting to know the community towards sign language is still low at 57\%,2) the level of skills using sign language is still low at $83 \%, 3$ ) the importance level of sign language according the community is $81 \%$, 4) The level of community needs to learn Sign Language is obtained by 88\%, and 5) The level of selection of the right media for learning Sign Language, $74 \%$ of respondents choose media in the form of a smartphone application. The validity of the interactive media prototype introduction BISINDO sign language developed in terms of substance that is the suitability of sign language in the application obtained a validator rating of $89.33 \%$, then in terms of the media obtained a validator value of $89.67 \%$. It can be concluded that the interactive media prototype in the form of a smartphone application that was developed very well in terms of substance and media so that it is very feasible or valid to be used in the introduction of BISINDO sign language.
\end{abstract}

Keywords: Sign Language, BISINDO, Interactive Media, Augmented Reality 


\section{PENDAHULUAN}

Isu pemenuhan hak-hak disabilitas merupakan isu internasional yang telah diperjuangkan oleh semua negara baik negara maju maupun negara berkembang. Usaha pemerintah Indonesia dalam memenuhi hak-hak disabilitas sudah tertuang dalam Convention On The Rights of Persons with Disabilities yang diatur dalam UndangUndang No 19 Tahun 2011 mengenai aksesibilitas. Undang-Undang No. 19 Tahun 2011 pasal 9 ayat 2 menyebutkan bahwa salah satu bentuk aksesibilitas bagi penyandang disabilitas adalah dapat berupa penyediaan bentuk-bentuk bantuan salah satunya bahasa isyarat bagi tunarungu [1].

Tunarungu atau dikenal dengan istilah tuli, adalah gangguan pendengaran sehingga memberikan hambatan dalam berkomunikasi. Bahasa isyarat merupakan bahasa yang biasa digunakan dalam berkomunikasi secara manual baik melalui bahasa tubuh maupun dengan gerak bibir [2]. Melalui bahasa isyarat tunarungu dapat berkomunikasi dengan lingkungan sekitarnya. Di Indonesia, terdapat dua bahasa isyarat yang sering digunakan yaitu Sistem Isyarat Bahasa Indonesia (SIBI) dan Bahasa Isyarat Indonesia (BISINDO). Tunarungu saat ini lebih banyak menggunakan BISINDO dalam berkomunikasi dikarenakan BISINDO merupakan bahasa ibu dan bahasa isyarat alami budaya asli Indonesia sehingga mudah dimengerti saat digunakan dalam keseharian [3].

Dalam memenuhi hak-hak disabilitas, khususnya tunarungu, tidak hanya diperlukan pengembangan akomodasi bahasa isyarat yang baik, tetapi juga dukungan dari lingkungan sosial sekitar. Penerimaan masyarakat terhadap tunarungu dapat mendukung terjadinya sosial interaksi yang baik dalam mewujudkan masyarakat yang inklusif. Begitu pula sebaliknya, kurangnya kepedulian masyarakat terhadap bahasa isyarat membuat tunarungu mengalami kesulitan dalam kehidupan sosialnya [4]. Berdasarkan hal tersebut perlu adanya sosialisasi kepada masyarakat tentang bagaimana cara berkomunikasi dengan tunarungu menggunakan bahasa isyarat, salah satunya menggunakan Bahasa isyarat Indonesia (BISINDO).

Untuk bisa belajar dan menggunakan bahasa isyarat dapat dilakukan dengan banyak cara, salah satunya melalui media interaktif. Media interaktif yang akan dikembangkan menggunakan teknologi Augmented Reality atau AR. Augmented Reality (AR) merupakan teknologi yang menggabungkan objek maya ke dalam lingkungan nyata pengguna lalu memproyeksikannya dalam waktu yang nyata [5]. Media interaktif berbasis augmented reality dengan substansi bahasa isyarat BISINDO dapat dikemas secara menarik melalui benda-benda yang biasa digunakan di masyarakat, sehingga diharapkan dapat menjadi salah satu bentuk sosialisasi bahasa isyarat BISINDO yang menarik bagi masyarakat, mudah ditemukan, biasa digunakan dan menciptakan lapangan pekerjaan baru bagi tunarungu.

\section{Konsep Hambatan Pendengaran}

Tunarungu berarti hambatan pendengaran yang sangat parah, anak mengalami gangguan dalam memproses informasi linguistik dengan mengggunakan pendengaran mereka, baik dengan menggunakan alat bantu pendengaran ataupun tidak menggunakan yang memiliki dampak pada prestasi akademik anak [6].

Tunarungu terdiri dari beberapa klasifikasi [7], yaitu:
1) Slight Loses
Tunarungu sangat ringan $(20-30 \mathrm{~dB})$.
2) Mild Loses
Tunarungu ringan (30-40 dB).
3) Moderate Loses
Tunarungu sedang $(40-60 \mathrm{~dB})$.
4) Severe Loses
Tunarungu berat (60-75 dB).
5) Profoundly Loses
Tunarungu sangat berat ( $75 \mathrm{~dB}$ ke atas).

Berdasarkan klasifikasi tersebut, penderita tunarungu juga memiliki beberapa karakteristik sebagai berikut:

\section{1) Karakteristik intelektual}

Kriteria persepsi pembelajaran dan ingatan, tidak ada perbedaan yang signifikan antara anak yang mendengar dan anak tunarungu. sehingga tunarungu tidak memiliki kekurangan dalam masalah intelektual.

\section{2) Karakteristik bahasa dan bicara}

Pemahaman bahasa lisan pasti terlambat dipahami oleh anak tunarungu, tetapi dengan intervensi yang dini dan pembiasaan, terdapat anak tunarungu yang mampu melakukan percakapan, pidato sesuai dengan anak-anak seusianya.

\section{3) Karakteristik sosial dan emosi}

Beberapa ciri atau sifat yang sering ditemukan pada penderita tunarungu antara lain [8]:

a) Sifat ego yang lebih besar daripada mendengar.

b) Sifat kaku, sikap kurang luwes dalam memandang dunia dan tugas-tugas dalam kesehariannya. 
c) Perasaan ragu-ragu dan khawatir seiring dengan pengalaman yang dialami secara terus-menerus

Berdasarkan karakteristik tersebut, maka penderita tunarungu membutuhkan bantuan dalam hal berikut:

1) Alat bantu dengar. Suatu alat bantu dengar pada dasarnya adalah versi kecil dari sistem alat pengeras suara.

2) Mengubah cara-cara berkomunikasi. Ada beberapa cara dalam melakukan komunikasi dengan tunarungu, yakni metode isyarat, oral dan komtal.

a) Isyarat menggunakan bibir dan tangan sebagai alat bantu komunikasi.

b) Oral menggunakan teknik membaca gerakan bibir dalam berkomunikasi.

c) Komtal atau komunikasi total menggunakan kedua teknik isyarat dan oral.

Bahasa Isyarat Indonesia (BISINDO)

Bahasa isyarat merupakan bahasa dengan mengutamakan komunikasi secara manual, bahasa tubuh, dan gerakan bibir dalam berkomunikasi. Dalam berkomunikasi dengan bahasa isyarat, digunakan bentuk, arah, dan pergerakan tangan yang diikuti dengan gerakan bibir, badan serta ekspresi wajah dalam menyampaikan maksud seseorang. Bahasa isyarat yang telah ada dan digunakan di dunia antara lain adalah American Sign Language (ASL), French Sign Language (LSF), German Sign Language (DGS) dan Arabic Sign Language (ArSL) [9].

Di Indonesia ada dua bahasa isyarat yang digunakan yaitu Sistem Bahasa Isyarat Indonesia atau SIBI dan Bahasa Isyarat Indonesia atau BISINDO. [3]. Perbedaan mendasar antara SIBI dan BISINDO adalah SIBI menggunakan äbjad sebagai panduan bahasa isyarat satu tangan, sementara BISINDO menggunakan dua tangan sebagai upaya komunikasi antar pengguna bahasa isyarat. Kemudian SIBI disusun oleh orang normal untuk digunakan tunarungu, sedangkan BISINDO dikembangkan oleh tunarungu yang tergabung dalam Gerakan Kesejahteraan Tunarungu Indonesia (GERKATIN). BISINDO digunakan untuk berkomunikasi antar tunarungu. Melalui BISINDO tunarungu dapat mengekspresikan dirinya sesuai hak yang dimilikinya, dan untuk berkomukasi dengan lingkunganya. BISINDO saat ini sedang disosialisasikan bersama GERKATIN untuk dapat menjadi bahasa isyarat yang berpayung hukum dan sah untuk digunakan oleh seluruh tunarungu di Indonesia [10].
Kecepatan dan kepraktisannya dari BISINDO membuat lebih mudah untuk memahami dan mengerti bagi kaum tunarungu walaupun tidak mengikuti faedah tata bahasa dari bahasa Indonesia [11]. Abjad Bahasa isyarat Indonesia (BISINDO) dapat dilihat pada gambar 1 .



Gambar 1. Abjad dalam BISINDO

\section{Media Interaktif}

Media interaktif merupakan sebuah media penyampaian yang menyajikan materi dengan memamanfaatkan penggunaan komputer kepada penonton, pengguna yang tidak hanya mendengar dan melihat melalui video dan suara, tetapi juga dapat memberikan respon yang aktif serta respon itu yang menentukan kecepatan dan sekuensi penyajian [12]. Media interaktif memiliki unsur audio-visual (termasuk animasi) dan disebut interaktif karena media ini dirancang dengan melibatkan respon pemakai secara aktif. Maka, dapat disimpulkan bahwa media interaktif adalah alat perantara yang dirancang khusus dengan pemanfaatan komputer menggunakan unsur seperti suara (audio), gambar (visual) dan tulisan (teks) untuk menyampaikan suatu pesan [13].

Media berdasarkan indera yang terlibat terbagi atas:

1) Media Audio

Media audio yaitu media yang melibatkan indera pendengaran dan hanya mampu memanipulasi kemampuan suara. Pesan verbal audio yakni bahasa lisan atau kata-kata, dan pesan nonverbal audio adalah seperti bunyibunyian dan vokalisasi, seperti gerutuan, gumam, musik, dan lain-lain.

2) Media Visual

Media visual yaitu media yang melibatkan indera penglihatan. Yang termasuk dalam jenis 
media ini adalah media cetak-verbal, media cetak-grafis, dan media visual non-cetak.

\section{3) Media Audio Visual}

Media audio visual yaitu media yang melibatkan indera pendengaran dan penglihatan secara sekaligus dalam suatu proses. Sifat pesan yang dapat disalurkan melalui media dapat berupa pesan verbal dan non-verbal yang terdengar layaknya media visual juga pesan verbal yang terdengar layaknya media audio diatas.

\section{Augmented Reality}

Augmented Reality (AR) adalah konsep pelapisan konten visual (seperti grafik) di atas pemandangan dunia nyata seperti yang terlihat melalui sebuah kamera [14]. AR merupakan sebuah konsep menambahkan dunia nyata dengan dunia maya. Meskipun menggunakan lingkungan virtual yang diciptakan oleh komputer grafis, taman bermain utamanya adalah lingkungan nyata [15]. Augmented Reality adalah proses penggabungan benda-benda nyata dan maya di lingkungan nyata, berjalan secara interaktif dalam waktu nyata, dan terdapat integrasi antar benda dalam tiga dimensi, Penggabungan benda nyata dan maya dimungkinkan dengan teknologi tampilan yang sesuai, interaktivitas dimungkinkan melalui perangkat perangkat input tertentu, dan integrasi yang baik memerlukan penjejakan yang efektif [16].

AR dapat digunakan dengan PC atau dengan smartphone. Kamera mengenali gambar yang telah ditentukan (pengenalan gambar) dan menampilkan konten digital pada gambar yang ditandai. Konten digital dapat berupa informasi, gambar atau video yang menambahkan keadaan nyata. Tujuan dari AR adalah mengambil dunia nyata sebagai dasar dengan menggabungkan beberapa teknologi virtual dan menambahkan data konstektual agar pemahaman manusia sebagai penggunanya menjadi semakin jelas. Data konstektual ini dapat berupa komentar audio, data lokasi, konteks sejarah, atau dalam bentuk lainnya [17].

\section{METODE}

Penelitian ini menggunakan pendekatan Research and Development (R\&D). Penelitian dan pengembangan merupakan proses atau metode yang digunakan untuk memvalidasi dan mengembangkan sebuah produk [18]. Produk dapat berupa benda seperti buku teks, film untuk pembelajaran, dan software (perangkat lunak) komputer, tetapi juga metode seperti metode mengajar, dan program.

Kegiatan research digunakan untuk melakukan mengidentifikasi permasalahan yang terjadi atau state of the art di lapangan mengenai 38 penerimaan bahasa isyarat BISINDO pada masyarakat umum dan kebutuhannya bagi tunarungu. Kegiatan development dilakukan untuk mengembangkan aplikasi media interaktif pengenalan bahasa isyarat BISINDO berbasis augmented reality.

Penelitian ini dibagi ke dalam dua tahap seperti Gambar 2. Tahap pertama dilakukan pengkajian permasalahan yang ada dilapangan mengenai penerimaan bahasa isyarat BISINDO pada masyarakat umum dan kebutuhannya bagi tunarungu. Hasil temuan tersebut nanti dipetakan dalam bentuk rumusan masalah, kemudian merumuskan beberapa pilihan alternatif sebagai solusi atau masukan dalam memperbaiki persepsi masyarakat terhadap tunarungu dan bahasa isyarat. Tahap kedua memfokuskan pada pengembangan prototype media interaktif bahasa isyarat BISINDO berbasis augmented reality mulai dari tahap desain, pengembangan dan validasi oleh validator dari aspek media dan substansi isi.

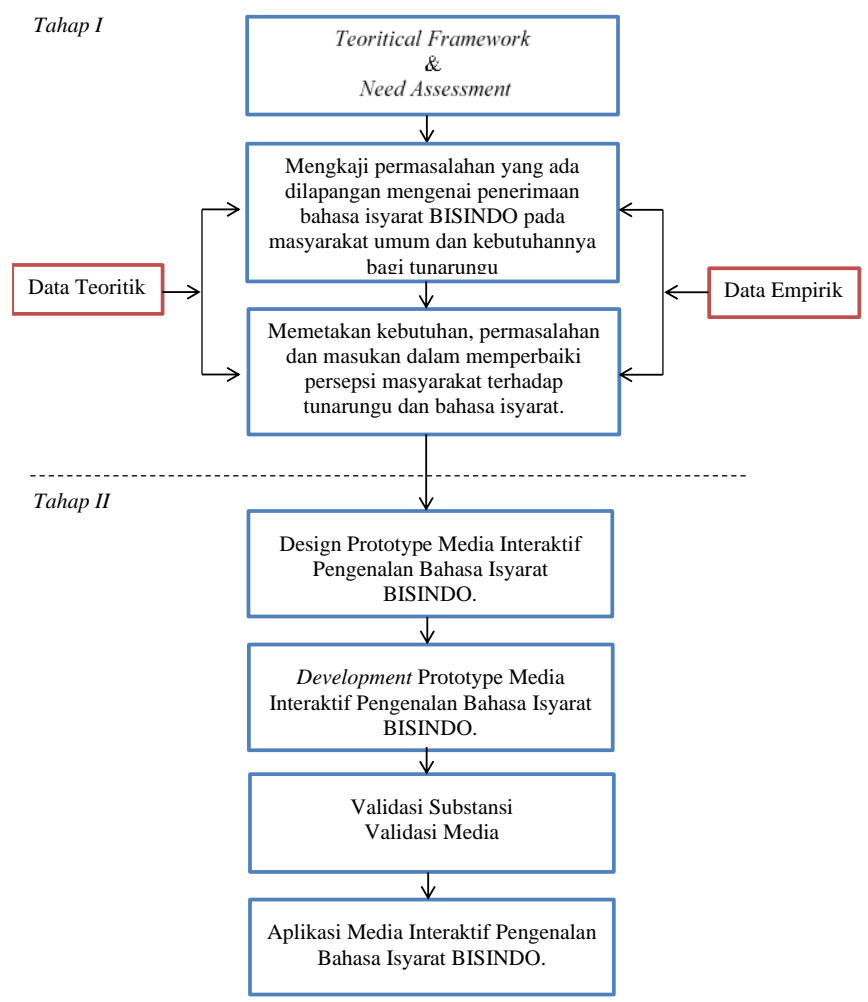

Gambar 2. Prosedur Pengembangan

\section{Populasi Penelitian}

Populasi dalam penelitian ini adalah tunarungu yang manjadi bagian dari kelompok Gerkatin dan masyarakat umum di Kota Padang. Sampel penelitian yang diambil menggunakan teknik purposive sampling. Sampel penelitian adalah tunarungu di Gerkatin Padang dan 100 orang dari masyarakat umum yang dipilih dari berbagai profesi 
seperti pelajar, mahasiswa, pekerja, dan orang tua di Kota Padang.

\section{Instrumen Penelitian}

Teknik pengumpulan data yang digunakan disesuaikan dengan tahapan penelitian. Instrumen penelitian yang digunakan berupa lembar angket untuk mengetahui:

1) Tingkat mengenal masyarakat terhadap Bahasa isyarat.

2) Tingkat keterampilan menggunakan Bahasa isyarat.

3) Tingkat pentingnya Bahasa isyarat menurut masyarakat.

4) Tingkat kebutuhan masyarakat untuk belajar Bahasa isyarat.

5) Tingkat pemilihan media yang tepat untuk belajar Bahasa isyarat.

Kemudian untuk validasi media interaktif juga menggunakan angket yang akan diisi dan dinilai oleh validator baik dari segi aspek substansi dan segi aspek media. Untuk validasi subtansi dan media terdiri dari beberapa aspek penilaian sebagai berikut:

Tabel 1. Aspek Penilaian Subtansi dan Media

\begin{tabular}{ll} 
Substansi & Media \\
\hline Kesesuaian Bahasa & Antarmuka \\
Konsistensi & Interaktivitas \\
Animasi 3D & Navigasi \\
Kelengkapan Abjad & Kecepatan Respon \\
Panduan Penggunaan & Kemudahan Penggunaan \\
\hline
\end{tabular}

Tabel 2. Skala Likert

\begin{tabular}{ll}
\hline Keterangan & Skor \\
\hline Sangat Baik $(\mathrm{SB})$ & 5 \\
Baik $(\mathrm{C})$ & 4 \\
Cukup Baik $(\mathrm{CB})$ & 3 \\
Kurang Baik $(\mathrm{KB})$ & 2 \\
Tidak Baik $(\mathrm{TB})$ & 1 \\
\hline
\end{tabular}

Rumus untuk menghitung skor dari lembar validasi substansi dan media aplikasi adalah sebagai berikut:

$$
v=\frac{\sum x \text { validator }}{\sum x \max } \times 100
$$

Keterangan:

$$
\begin{aligned}
& v=\text { validitas } \\
& \sum x \text { validator }=\text { jumlah skor validator } \\
& \sum x \text { max }=\text { skor maksimum }
\end{aligned}
$$

Tabel 3. Kriteria Validasi

\begin{tabular}{lll}
\hline Persentase & Kriteria & Ket. \\
\hline $80-100 \%$ & Sangat Baik & Valid \\
$60-79 \%$ & Baik & Valid \\
$40-59 \%$ & Cukup Baik & Valid \\
$20-39 \%$ & Kurang Baik & Tidak Valid \\
$0-19 \%$ & Tidak Baik & Tidak Valid \\
\hline
\end{tabular}

\section{HASIL DAN PEMBAHASAN}

Berdasarkan hasil pengumpulan data persepsi masyarakat terhadap bahasa isyarat, diketahui hasil sebagai berkut:

\section{1) Tingkat mengenal masyarakat terhadap Bahasa isyarat.}

Tabel 4. Kriteria Persepsi Tingkat (1)

\begin{tabular}{lll}
\hline Persentase & Kriteria & Ket. \\
\hline $80-100 \%$ & Sangat Tidak Tahu & STT \\
$60-79 \%$ & Tidak Tahu & TT \\
$40-59 \%$ & Cukup Tahu & CT \\
$20-39 \%$ & Tahu & T \\
$0-19 \%$ & Sangat Tahu & ST \\
\hline
\end{tabular}

Tabel 5. Tingkat mengenal bahasa isyarat.

\begin{tabular}{ccc} 
Kriteria & Jumlah & Persentase \\
\hline STT & 25 & $25 \%$ \\
TT & 32 & $32 \%$ \\
CT & 23 & $23 \%$ \\
T & 15 & $15 \%$ \\
ST & 5 & $5 \%$ \\
\hline Jumlah & 100 & $100 \%$ \\
\hline
\end{tabular}

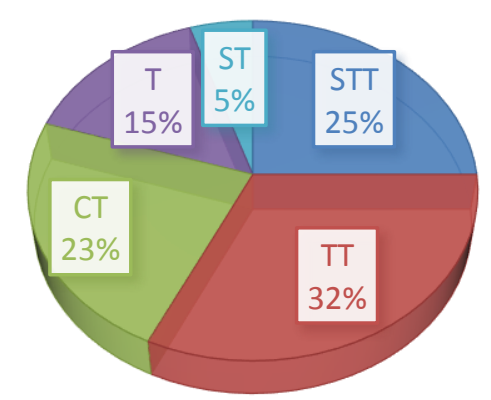

Gambar 3. Tingkat mengenal Bahasa isyarat.

Berdasarkan Tabel 4, Tabel 5 dan Gambar 3, diketahui bahwa dari 100 orang responden, 32\% sangat tidak tahu mengenai Bahasa isyarat, $25 \%$ tidak tahu mengenai Bahasa isyarat, sehingga dapat disimpulkan sebesar 57\% responden tidak mengenal bahasa isyarat.

2) Tingkat keterampilan menggunakan Bahasa isyarat.

Tabel 6. Kriteria Persepsi Tingkat (2)

\begin{tabular}{lll}
\hline Persentase & Kriteria & Ket. \\
\hline $80-100 \%$ & Sangat Tidak Mampu & STM \\
$60-79 \%$ & Tidak Mampu & TM \\
$40-59 \%$ & Cukup Mampu & CM \\
$20-39 \%$ & Mampu & M \\
$0-19 \%$ & Sangat Mampu & SM \\
\hline
\end{tabular}

Tabel 7. Tingkat keterampilan menggunakan Bahasa isyarat.

\begin{tabular}{ccc}
\hline Kriteria & Jumlah & Persentase \\
\hline STM & 56 & $56 \%$ \\
TM & 27 & $27 \%$ \\
CM & 9 & $9 \%$ \\
M & 8 & $8 \%$ \\
SM & 0 & $0 \%$ \\
\hline Jumlah & 100 & $100 \%$ \\
\hline
\end{tabular}




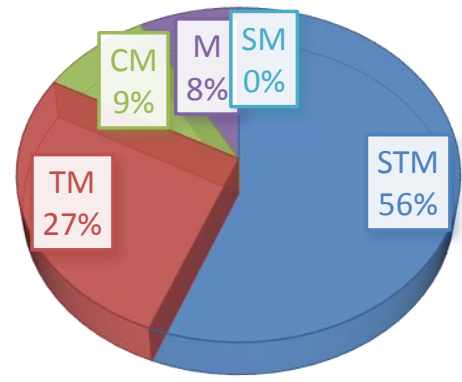

Gambar 4. Tingkat keterampilan menggunakan Bahasa isyarat.

Berdasarkan Tabel 6, Tabel 7 dan Gambar 4, diketahui bahwa dari 100 orang responden, 56\% sangat tidak mampu menggunakan Bahasa isyarat, $27 \%$ tidak mampu menggunakan Bahasa isyarat, sehingga dapat disimpulkan sebesar $83 \%$ responden tidak terampil dalam menggunakan bahasa isyarat.

3) Tingkat pentingnya Bahasa isyarat menurut masyarakat.

Tabel 8. Kriteria Persepsi Tingkat (3)

\begin{tabular}{lll}
\hline Persentase & Kriteria & Ket. \\
\hline $80-100 \%$ & Sangat Tidak Penting & STP \\
$60-79 \%$ & Tidak Penting & TP \\
$40-59 \%$ & Cukup Penting & CP \\
$20-39 \%$ & Penting & P \\
$0-19 \%$ & Sangat Penting & SP \\
\hline
\end{tabular}

Tabel 9. Tingkat pentingnya Bahasa isyarat.

\begin{tabular}{ccc}
\hline Kriteria & Jumlah & Persentase \\
\hline STP & 4 & $4 \%$ \\
TP & 1 & $1 \%$ \\
CP & 14 & $14 \%$ \\
P & 21 & $21 \%$ \\
SP & 60 & $60 \%$ \\
\hline Jumlah & 100 & $100 \%$ \\
\hline
\end{tabular}

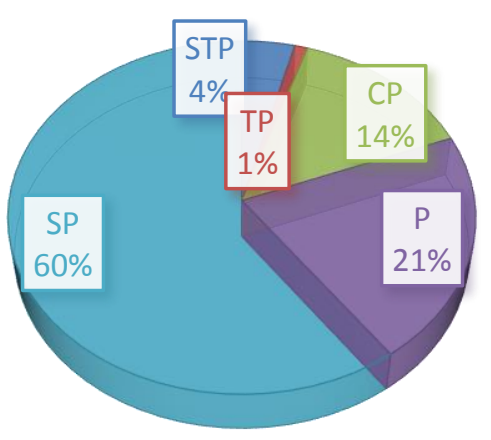

Gambar 5. Tingkat pentingnya Bahasa isyarat.

Berdasarkan Tabel 8, Tabel 9 dan Gambar 5, diketahui bahwa dari 100 orang responden, $60 \%$ mengatakan sangat penting penggunaan Bahasa isyarat untuk masyarakat, $21 \%$ mengatakan penting penggunaan Bahasa isyarat, sehingga dapat disimpulkan sebesar $81 \%$ responden berpendapat penggunaan bahasa isyarat oleh masyarakat itu penting.
4) Tingkat kebutuhan masyarakat untuk belajar Bahasa isyarat.

Tabel 10. Kriteria Persepsi Tingkat (4)

\begin{tabular}{lll}
\hline Persentase & Kriteria & Ket. \\
\hline $67-100 \%$ & Sangat Butuh & SB \\
$34-66 \%$ & Cukup Butuh & CB \\
$0-33 \%$ & TIdak Butuh & TB \\
\hline
\end{tabular}

Tabel 11. Tingkat kebutuhan untuk belajar Bahasa isyarat.

\begin{tabular}{ccc}
\hline Kriteria & Jumlah & Persentase \\
\hline SB & 67 & $67 \%$ \\
CB & 21 & $21 \%$ \\
TB & 12 & $12 \%$ \\
\hline Jumlah & 100 & $100 \%$ \\
\hline
\end{tabular}

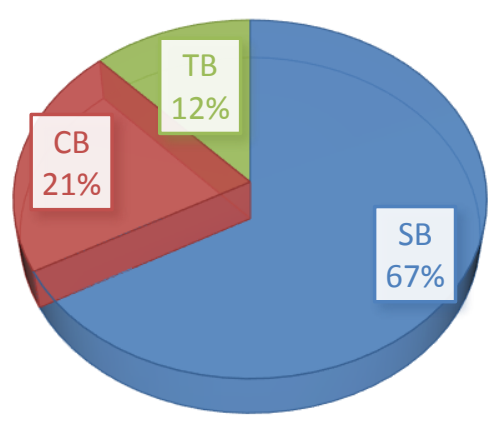

Gambar 6. Tingkat keterampilan menggunakan Bahasa isyarat.

Berdasarkan Tabel 10, Tabel 11 dan Gambar 6, diketahui bahwa dari 100 orang responden, 67\% menyatakan sangat butuh untuk belajar menggunakan Bahasa isyarat, 21\% cukup butuh untuk belajar menggunakan Bahasa isyarat, sehingga dapat disimpulkan sebesar $88 \%$ responden butuh untuk belajar bahasa isyarat.

5) Tingkat pemilihan media yang tepat untuk belajar Bahasa isyarat.

Tabel 12. Pemilihan media untuk belajar Bahasa isyarat.

\begin{tabular}{lcc}
\hline Media & Jumlah & Persentase \\
\hline Aplikasi Android & 74 & $74 \%$ \\
Aplikasi Komputer & 6 & $6 \%$ \\
Blog atau Vlog & 4 & $4 \%$ \\
Buku & 11 & $11 \%$ \\
Pelatihan Bahasa & 2 & $2 \%$ \\
Seminar & 3 & $3 \%$ \\
Tidak Menjawab & 0 & $0 \%$ \\
\hline Jumlah & 100 & $100 \%$ \\
\hline
\end{tabular}

Berdasarkan Tabel 12, dan Gambar 7, diketahui bahwa dari 100 orang responden, 74\% memilih media berupa aplikasi android untuk belajar menggunakan Bahasa isyarat. Sehingga dalam penelitian ini sangat perlu untuk mengembangkan sebuah media interaktif pengenalan Bahasa isyarat BISINDO berbasis Augmented Reality berupa aplikasi berbasis android yang dapat digunakan oleh masyarakat. 


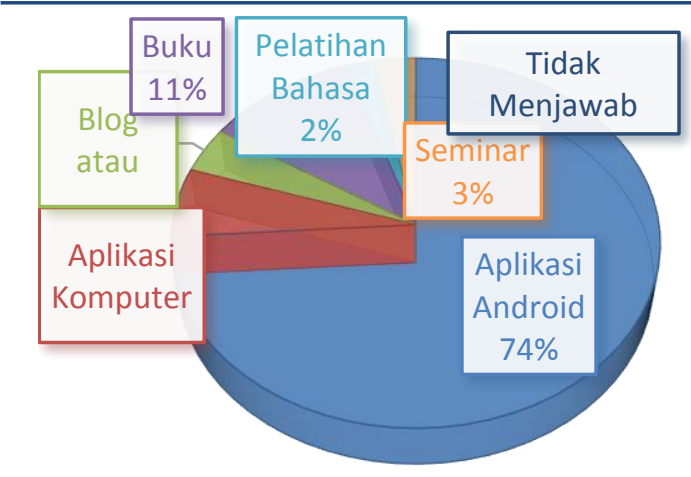

Gambar 7. Pemilihan media yang tepat belajar Bahasa isyarat. Pengembangan Media Interaktif

Berdasarkan data diatas, sudah dapat diambil kesimpulan bahwa masyarakat menginginkan media belajar Bahasa isyarat yang mudah dipelajari dan diakses melalui smartphone yaitu berupa aplikasi android. Oleh karena itu, maka perlu dikembangkan aplikasi berbasis augmented reality untuk belajar Bahasa isyarat. Workflow Aplikasi Augmented Reality BISINDO (Belajar bahasa isyarat BISINDO dengan cara yang menyenangkan) pada Gambar 8.

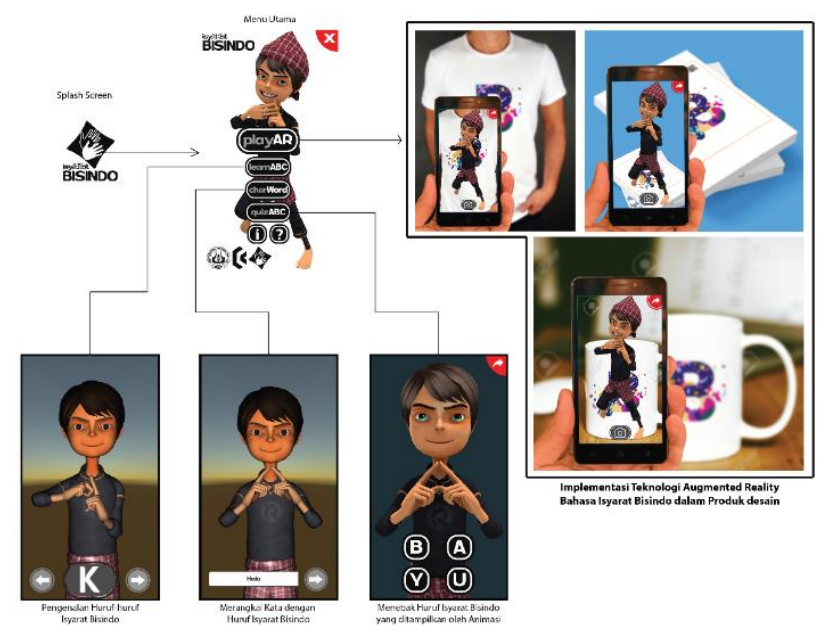

Gambar 8. Workflow Aplikasi "isyARat BISINDO"

Tabel 13. Penjelasan Aplikasi "isyARat BISINDO"

\begin{tabular}{ll}
\hline No. & \multicolumn{1}{c}{ Ket. } \\
\hline 1 & $\begin{array}{l}\text { Logo aplikasi Media } \\
\text { Interaktif Pengenalan } \\
\text { bahasa isyarat Bisindo } \\
\text { berbasis Augmented } \\
\text { Reality berwarna hitam } \\
\text { dan putih untuk } \\
\text { menampilkan kesan } \\
\text { sederhana namun } \\
\text { modern. }\end{array}$ \\
\hline
\end{tabular}



4


6

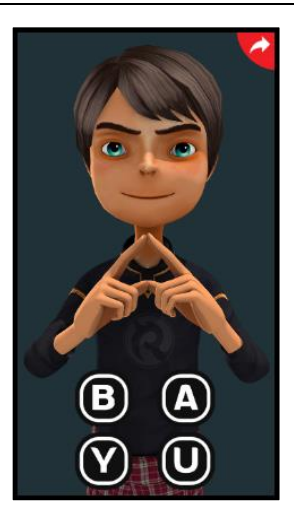

Halaman Learn ABC

pada halaman ini, pengguna dapat mempelajari hurufhuruf isyarat BISINDO yang diperagakan oleh karakter Animasi 3D.

Halaman Char Word

Pada halaman ini, pengguna diminta untuk memasukkan kata dalam kolom yang disediakan, setelah itu sistem secara otomatis akan mengkonversi kata yang diinputkan menjadi rangkaian huruf-huruf BISINDO yang diperagakan oleh karakter animasi $3 \mathrm{D}$.

Halaman Quiz ABC

Pada halaman ini, pengguna harus menebak huruf Bisindo yang di tampilkan oleh karakter animasi 3D pada kolom yang disediakan. Laman ini dapat digunakan oleh pengguna untuk dapat digunakan sejauh mana pengguna mengingat huruf-huruf isyarat BISINDO. 

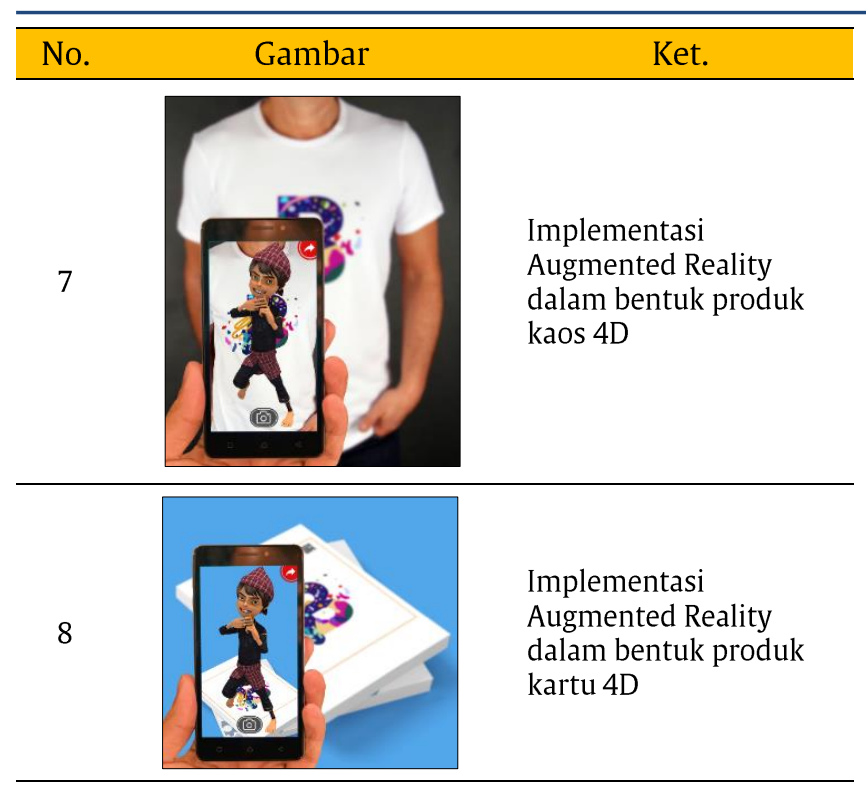

9

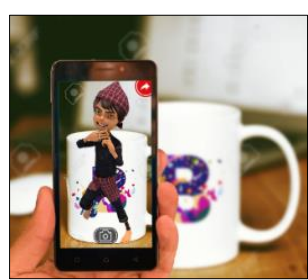

Implementasi

Augmented Reality

dalam bentuk produk

Gelas Mug 4D

Pada Tabel 13 dapat dilihat secara detil penjelasan mengenai media interaktif pengenalan Bahasa isyarat yang dikembangkan berupa aplikasi android yang diberi nama isyARat BISINDO.

\section{Validasi Subtansi}

Validasi media interaktif menggunakan angket yang akan diisi oleh validator. Media divalidasi dari segi aspek penilaian substansi dan aspek penilaian media. Berikut dapat dilihat hasil dari validasi pada tabel 14 dan tabel 15:

Tabel 14. Validasi Substansi

\begin{tabular}{lllll}
\hline Aspek & V1 & V2 & V3 & Avg. \\
\hline Kesesuaian Bahasa & 17 & 18 & 20 & 18,33 \\
Konsistensi & 15 & 17 & 18 & 16,67 \\
Animasi 3D & 20 & 18 & 20 & 19,33 \\
Kelengkapan Abjad & 18 & 18 & 18 & 18,00 \\
Panduan Penggunaan & 17 & 17 & 18 & 17,33 \\
\hline Total & 87 & 88 & 94 & 89,67 \\
\hline
\end{tabular}

Berdasarkan hasil validasi substansi diperoleh sebesar $89,67 \%$, sehingga secara substansi dari media dikategorikan sangat baik. Bahasa isyarat yang ada dalam aplikasi sudah sesuai dengan bahasa isyarat Indonesia (BISINDO) yang digunakan komunitas tuli. Aplikasi dapat disosialisasikan kepada masyarakat. Aplikasi sangat menarik untuk menarik minat masyarakat untuk belajar Bahasa isyarat. Penambahan kosa kata mungkin dapat dilakukan untuk memperbanyak kosakata yang dapat dipelajari masyarakat.

\begin{tabular}{lllll} 
Tabel 15. Validasi Media & & & & \\
\hline Aspek & V1 & V2 & V3 & Avg. \\
\hline Antarmuka & 19 & 20 & 18 & 19,00 \\
Interaktivitas & 19 & 17 & 18 & 18,00 \\
Navigasi & 16 & 17 & 16 & 16,33 \\
Kecepatan Respon & 17 & 17 & 18 & 17,33 \\
Kemudahan Penggunaan & 18 & 18 & 20 & 18,67 \\
\hline Total & 89 & 89 & 90 & 89,33 \\
\hline
\end{tabular}

Berdasarkan hasil validasi dari aspek media diperoleh sebesar 89,33\%, sehingga dari segi media mulai dari antarmuka, interaktivitas, tombol navigasi, kecepatan respon dari aplikasi, dan kemudahan penggunaan media aplikasi dapat dinyatakan dalam kategori sangat baik. Aplikasi yang dibuat adalah aplikasi yang dapat digunakan oleh hampir semua lapisan masyarakat yang telah terbiasa mengoperasikan smartphone yang menggunakan sistem operasi android. Desain dibuat sederhana (user friendly) agar mudah digunakan oleh pengguna awam. Aplikasi juga didesain agar dapat digunakan oleh pengguna yang ingin mengenal huruf isyarat BISINDO yang di peragakan oleh karakter animasi 3 Dimensi tanpa harus menggunakan penanda AR. Desain penanda AR dapat di aplikasikan pada media kartu, buku, pin, mug dan kaos yang memiliki potensi nilai bisnis tersendiri.

Berdasarkan kriteria validasi baik dari segi aspek substansi dan aspek media berada pada rentang persentase:

$$
80 \% \geq v \leq 100 \% \text { (sangat baik, valid) }
$$

\section{KESIMPULAN}

Pada dasarnya, masyarakat memiliki keinginan untuk mempelajari bahasa isyarat, dan merasa bahwa bahasa isyarat penting untuk menjalin komunikasi antara sesama. Hal ini diperkuat dari hasil analisis kualitatif yang menyebutkan bahwa masyarakat yang belum mengenal bahasa isyarat dengan baik merasa bahasa isyarat itu penting karena beberapa hal berikut:

1) Bahasa isyarat adalah suatu komunikasi bagi yang ada hambatan pendengaran.

2) Untuk membantu satu sama lain

3) Memudah komunikasi

4) Sebagai keterampilan untuk bisa berkomunikasi terhadap orang yang memiliki hambatan tersebut

5) Supaya orang yang satu dengan yang lain mengerti

Berdasarkan hasil data angket dari masyarakat mengenai pengenalan bahasa isyarat BISINDO, menyatakan bahwa masyarakat merasa bahwa Bahasa isyarat itu sangat penting untuk dipelajari. Kemudian 74\% responden juga memilih media yang 
digunakan dalam belajar Bahasa isyarat berupa aplikasi android, karena kecenderungan masyarakat yang gemar menggunakan smartphone. Sehingga Media interaktif pengenalan Bahasa isyarat BISINDO berupa aplikasi android menjadi solusi yang tepat.

Media interaktif pengenalan Bahasa isyarat BISINDO sudah melewati proses validasi oleh validator. Berdasarkan hasil validasi substansi dan validasi media, dapat diambil kesimpulan bahwa aplikasi yang dikembangkan termasuk dalam kategori sangat baik dan valid, yaitu memperoleh penilaian validator sebesar $89.67 \%$ untuk aspek substansi dan $89.33 \%$ untuk aspek media. Sehingga media interaktif pengenalan Bahasa isyarat BISINDO yang dikembangkan dinyatakan sangat layak untuk digunakan oleh masyarakat dalam pengenalan Bahasa isyarat BISINDO.

\section{SARAN}

Berdasarkan kesimpulan tersebut, maka disarankan:

1) Masyarakat perlu mendapat pembelakalan atau latihan dalam menggunakan media interaktif yang telah di validasi.

2) Dapat ditambahkan pilihan karakter animasi 3D yang lain pada aplikasi.

3) Media perlu diimplementasikan secara luas untuk mengetahui efektivitas secara mendetil.

\section{DAFTAR PUSTAKA}

[1] "PENGESAHAN CONVENTION ON THE RIGHTS OF PERSONS WITH DISABILITIES (KONVENSI MENGENAI HAK-HAK PENYANDANG DISABILITAS)."

[2] Z. Nikolawatin, P. Setyosari, and S. Ulfa, "PENGEMBANGAN MEDIA TUTORIAL BAHASA ISYARAT UNTUK SISWA TUNARUNGU SLB BC KEPANJEN," JINOTEP (Jurnal Inov. dan Teknol. Pembelajaran) Kaji. dan Ris. dalam Teknol. Pembelajaran, vol. 6, no. 1, pp. 15-22, Jul. 2019.

[3] R. A. Mursita, "RESPON TUNARUNGU TERHADAP PENGGUNAAN SISTEM BAHASA ISYARAT INDONESA (SIBI) DAN BAHASA ISYARAT INDONESIA (BISINDO) DALAM KOMUNIKASI," INKLUSI, vol. 2, no. 2, p. 221, Dec. 2015.

[4] C. Lee and S. A. Pott, "University students' attitudes towards deaf people: educational implications for the future," Deaf. Educ. Int., vol. 20, no. 2, pp. 80-99, Apr. 2018.

[5] J. Barrow, C. Forker, A. Sands, D. O' Hare, and W. Hurst, "Augmented Reality for Enhancing
Life Science Education," Vis. 2019-The Fourth Int. Conf. Appl. Syst. Vis. Paradig., 2019.

[6] D. J. Napoli and S. Liapis, Effort reduction in articulation in sign languages and dance, vol. 3, no. 1. Springer Singapore, 2019.

[7] M. Affendi, "Pengantar Psikopedagogik Anak Berkelainan," Mycol. Res., 2006.

[8] U. Bellugi and E. S. Klima, "Sign Language," in International Encyclopedia of the Social \& Behavioral Sciences: Second Edition, 2015.

[9] A. A. Gafar and J. Y. Sari, "Sistem Pengenalan Bahasa Isyarat Indonesia dengan Menggunakan Metode Fuzzy K-Nearest Neighbor," J. Ultim., vol. 9, no. 2, pp. 122-128, Apr. 2018.

[10] Fajri, Bayu Ramadhani and G. Kusumastuti, "Perceptions of 'Hearing' People on Sign Language Learning," in Proceedings of the 5th International Conference on Education and Technology (ICET 2019), 2019, vol. 382, no. ICET, pp. 364-367.

[11] A. Breva Yunanda, F. Mandita, and A. Primasetya Armin, "Pengenalan Bahasa Isyarat Indonesia (BISINDO) Untuk Karakter Huruf Dengan Menggunakan Microsoft Kinect," Fountain Informatics J., vol. 3, no. 2, p. 41, Nov. 2018.

[12] B. R. Fajri and Irfansyah, "CONMEDIA 2015 International Conference on New Media 2015," CONMEDIA 2015 - Int. Conf. New Media 2015, 2016.

[13] A. D. Samala, B. R. Fajri, and F. Ranuharja, "DESAIN DAN IMPLEMENTASI MEDIA PEMBELAJARAN BERBASIS MOBILE LEARNING MENGGUNAKAN MOODLE MOBILE APP," $J$. Teknol. Inf. dan Pendidik., vol. 12, no. 2, pp. 13-19, Dec. 2019.

[14] F. Wahyutama, F. Samopa, and $H$. Suryoytisongko, "Penggunaan Teknologi Augmented Reality Berbasis Barcode sebagai Sarana Penyampaian," J. Tek. Pomits, 2013.

[15] P. M. and F. Kishino, "Markerless Augmented Reality Pada Perangkat Android," E-Journal Tek. Inform., 2017.

[16] Y. G. Kim and W. J. Kim, "Implementation of augmented reality system for smartphone advertisements," Int. J. Multimed. Ubiquitous Eng., 2014.

[17] C. O. Karundeng, D. J. Mamahit, and B. A. 
Sugiarso, "Rancang Bangun Aplikasi Pengenalan Satwa Langka di Indonesia Menggunakan Augmented Reality," J. Tek. Inform., 2018.

[18] P. D. Sugiyono, metode penelitian kuantitatif, kualitatif,dan R\&D. 2016.

[19] E. Mulyatiningsih, Metode Penelitian Terapan Bidang Pendidikan. Bandung: Alfabeta., 2013. 